\title{
Highly Active Antiretroviral Therapy-Associated Metabolic Syndrome and Lipodystrophy: Pathophysiology and Current Therapeutic Interventions
}

\author{
Sanelisiwe Nzuza a, Sindiswa Zondia ${ }^{\mathrm{a}}$, Ranjendraparsad Hurchund ${ }^{\mathrm{a}}$, \\ Peter MO Owira ${ }^{a, b}$
}

\begin{abstract}
The use of highly active antiretroviral therapy (HAART) has extremely enhanced the clinical outcome of HIV disease with a decrease in mortality and morbidity. However, the inclusion of protease inhibitors (PIs) and nucleoside reverse transcriptase inhibitors (tNRTIs) has strongly been linked to the development of metabolic abnormalities and lipodystrophy. Lipodystrophy is defined by the loss of peripheral subcutaneous fat and central adiposity, mainly in the abdomen, breast and dorsocervical region. These disorders are reported to be cosmetically distressing and socially stigmatizing to many patients leading to decreased adherence to antiretroviral therapy. Metabolic syndrome precedes lipodystrophy leading to increased risk of diabetes and cardiovascular diseases. With a shifted trajectory of HIV/AIDS morbidity from immunodeficiency and opportunistic infections to metabolic complications, clinical management of these patients has therefore become more complex. Currently there are no evidence-based standard guidelines for the management of HIV-associated lipodystrophy. Several pharmacological interventions such as using anti-diabetic, anti-dyslipidemic drugs or hormone replacement therapy have been tried to effectively improve metabolic syndrome and lipodystrophy but have been hampered by low efficacy, drug interactions, or unwanted side-effects. Non-pharmacological interventions including surgical manipulations, dietary and lifestyle modifications have also been tried with limited success. This review focuses on the proposed mechanisms involved in the development of metabolic syndrome and lipodystrophy, and highlights suggested potential therapeutic interventions to prevent lipodystrophy associated with HAART.
\end{abstract}

Keywords: HAART; Glucose intolerance; Insulin resistance and dyslipidemia

Manuscript accepted for publication March 31, 2017

${ }^{a}$ Molecular and Clinical Pharmacology Research Laboratory, Department of Pharmacology, Discipline of Pharmaceutical Sciences, School of Health Sciences, University of KwaZulu-Natal, PO Box X5401, Durban, South Africa ${ }^{\mathrm{b}}$ Corresponding Author: PMO Owira, Molecular and Clinical Pharmacology Research Laboratory, Department of Pharmacology, Discipline of Pharmaceutical Sciences, School of Health Sciences, University of KwaZulu-Natal, PO Box X5401, Durban, South Africa. Email: owirap@ukzn.ac.za

doi: https://doi.org/10.14740/jem364w

\section{Introduction}

Highly active antiretroviral therapy (HAART) has led to a decline in HIV/AIDS-related illnesses associated morbidity and mortality $[1,2]$. In HAART, two nucleoside reverse transcriptase inhibitors (NRTIs) together with one non-nucleoside reverse transcriptase inhibitor (NNRTI) or a protease inhibitor (PI) (ritonavir-boosted) or more recently, raltegravir, (an integrase inhibitor) are used as first-line treatment [3]. The enhanced efficacy, reduced viral load, and increased $\mathrm{CD} 4^{+}$counts have reduced the risk of contracting opportunistic infections in patients on HAART [4]. However, despite significant benefits of HAART in transforming HIV infections from terminal to chronic illness, reports have emerged of associated metabolic complications such as metabolic syndrome and lipodystrophy which are known risk factors for type 2 diabetes mellitus and cardiovascular diseases [5-7].

Lipodystrophy is defined by the loss of peripheral subcutaneous fat (lipoatrophy) and central fat accumulation (lipohypertrophy), which may occur separately or co-exist in the same patient $[8,9]$. Lipoatrophy is associated with the loss of subcutaneous fat mainly in the face, arms, buttocks and lower limbs whereas lipohypertrophy is characterised by fat accumulation in the adipose tissues at the back of the neck "buffalo hump" or dorsocervical region, abdominal adiposity and mammary hypertrophy/gynecomastia [8-10]. The etiology of lipodystrophy syndrome is poorly understood but the incidence is estimated at $2-60 \%$ and $30 \%$ in adults and children on HAART, respectively $[9,11-13]$.

PIs have previously been linked to the development of lipodystrophy but it has now emerged that concurrent use with NRTIs has synergistic contribution to lipodystrophy and metabolic syndrome [14, 15]. Mynarcik et al investigated a large group of HIV-positive patients who were on either PIs, NRTIs or both for 12 months and reported that $54 \%$ of PI-treated patients developed lipodystrophy compared to $13 \%$ of NRTItreated patients and that NRTI-treated patients had a slower progression of fat loss which was accelerated when a PI was added [16]. Similarly, Carr et al reported that $64 \%$ of HIV individuals who were receiving PIs developed lipodystrophy within 10 months of treatment compared to $3 \%$ of treatment-naive patients [17]. Risk factors currently associated with HAARTrelated lipodystrophy include duration of therapy, female gender (lipohypertrophy), increased age, race (common in 
Caucasians), low $\mathrm{CD}^{+}{ }^{+}$counts, use of PIs and NRTIs (mainly thymidine analogues) in addition to HIV pathogenesis, genetic and environment factors [11, 18, 19].

Metabolic complications associated with lipodystrophy following HAART include glucose intolerance and insulin resistance, increased plasma total cholesterol (TC) and triglycerides (TG), decreased plasma concentrations of high-density lipoprotein cholesterol (HDL-C), and increased low-density lipoprotein cholesterol (LDL-C) [3, 19-21]. Several therapeutic interventions have been tried such as lifestyle modifications, cosmetic surgery, hormone replacement or nutritional therapies, switching antiretroviral components of individual drugs or development of newer and safer drugs to be incorporated into HAART with minimum successes. Anti-diabetic and antidyslipidemic agents have additionally been used as adjunct therapy but increased pill burden, enhanced drug toxicity, and potentially increased life-threatening drug interactions have limited their efficacy. This review therefore focuses on the molecular and pathophysiological mechanisms underlying HAART-associated lipodystrophy and proposes possible interventions that may be appropriate to mitigate the development of these conditions in vulnerable patients.

\section{Pathogenesis of HAART-Associated Metabolic Syndrome and Lipodystrophy}

\section{PIs and lipid metabolism}

PIs have been shown to suppress adipocyte differentiation [9, 22-24]. The catalytic site of HIV-protease, to which PIs bind shares approximately $63 \%$ of 12 -amino acid sequence homology with a region incorporating a lipid binding domain in the low-density lipoprotein receptor-related protein (LRP) and $58 \%$ with a $\mathrm{C}$-terminal region of the cytoplasmic retinoic acid binding protein type 1 (CRABP-1) $[15,17]$, respectively. Under normal circumstances, CRABP-1 binds to intracellular retinoic acid (RA) and accelerates its conversion to 9-cis-RA, a major ligand of the retinoic $X$ receptor (RXR) $[15,17,25$, 26]. Then, the heterodimerization of RXR with peroxisome proliferator-activated receptor-gamma (PPAR- $\gamma$ ) significantly enhances the binding affinity of 9-cis-RA to RXR [15, 17, 25]. The complex 9-cis-RA-RXR-PPAR- $\gamma$ thus enhances transcription of genes that prevent adipocytes from apoptosis and increases adipocyte differentiation. This is sabotaged by PIs which increase apoptosis and reduce differentiation of peripheral adipocytes [15, 17, 25]. PIs have further been reported to inhibit cytochrome P450 3A, which is required for the conversion of RA to cis-9-RA hence contributing to the impairment of peripheral adipocytes functions $[17,26,27]$ and also reduces the expression of PPAR- $\gamma$, leading to less differentiation of pre-adipocytes [25].

PIs are known to suppress the expression of sterol regulatory element binding proteins (SREBPs) which are transcriptional regulators of lipid synthesis genes leading to increased plasma concentrations of cholesterol and synthesis of fatty acids, and decreased storage of TG. These are typical congeners of lipodystrophy, dyslipidemia and insulin resistance [23, 28].
PIs also appear to inhibit proteasome-mediated breakdown of apolipoprotein B (apo B), resulting in overproduction of TGrich lipoproteins $[10,23,28]$. Recent data from cross-sectional studies have shown that HAART-treated patients had increased secretion and reduced clearance of very low-density lipoprotein (VLDL) particles, increased synthesis and reduced catabolism of apo B, elevated levels of pro-atherogenic residue lipoproteins and reduced activity of lipoproteins lipase compared to healthy individuals [28].

\section{PI-induced glucose intolerance and insulin resistance}

PIs contribute to the development of insulin resistance and hyperglycemia by blocking glucose disposal in skeletal muscles and adipose tissues $[22,23]$. It has been suggested that PIs directly block glucose uptake though suppressing glucose transporter protein isoform 4 (GLUT4, SLC2A4) activity leading to reduced glucose uptake and hyperglycemia [10, 22, 23, 29]. These effects appear to be caused by suppression of GLUT4 transport function and not translocation or interference with insulin signalling cascade [30].

Furthermore, PIs have been reported to impair insulin secretion in the pancreatic $\beta$ cells $[24,29]$ and also contribute to insulin resistance by inhibiting LDL-receptor activity leading to elevated plasma TG [10]. PI-induced insulin resistance is also potentiated by reduced conversion of pro-insulin to insulin, decreased secretion of adiponectin (which leads to increased hepatic gluconeogenesis and reduced glucose uptake by adipose tissue and skeletal muscles) and also down-regulates the expression of SREBP-1, a transcriptional regulator involved in lipid homeostasis [22, 24, 28].

\section{Effect of PIs on adipokines and proinflammatory cytokines}

Altered secretion of adipokines such as adiponectin, leptin and resistin, has been observed in lipodystrophic tissues in HIV patients $[2,24]$. Reduced circulating adiponectin is associated with insulin resistance, visceral fat accumulation, increased waist-to-hip ratio and body mass index (BMI) due to downregulation of its transcription factors SREB-1/PPAR- $\gamma$ by PIs [11, 24, 29-31]. Adiponectin has been shown to have anti-oxidant, anti-atherosclerotic, hypolipidemic and anti-inflammatory properties; hence, hypoadiponectinemia is associated with increased risk of cardiovascular diseases [11, 32-35]. Plasma adiponectin levels and tissue sensitivity appear to be suppressed by both antiretroviral therapy and lipodystrophy itself [24].

Leptin on the other hand is involved in energy homeostasis, glycemic control and lipid metabolism but PIs appear to have no effects on serum leptin expressions [24, 36, 37]. However, it has been suggested that the effects of leptin on HAART-treated individual depend on body stability between fat loss and increased gene expression, since in lipoatrophic patients, serum leptin levels were found to be reduced while in lipohypertrophic they were elevated [38-40]. Leptin deficiency has strongly been linked to impaired insulin sensitivity in normal individuals [24]. 
Unlike in rodents, human studies have suggested that resistin is not associated with the development of diabetes and metabolic syndrome although there is experimental evidence that resistin could act synergistically with antiretrovirals to inhibit adipocyte differentiation and promote peripheral fat loss [41-45]. Other adipokines that were found to be reduced in lipodystrophic subjects include retinol binding protein-4, visfatin, acylation-stimulating protein, omentin and vaspin [24].

Increased circulation of inflammatory cytokines such as tumour necrosis factor-alpha (TNF- $\alpha$ ) [18], plasminogen activator inhibitor 1 (PAI-1) [31] and interleukin (IL)-6 was also observed in adipose tissue from lipodystrophic individuals on HAART [32, 46, 47]. Mynarcik et al demonstrated high levels of soluble type 2 tumor necrosis factor- $\alpha$ receptor- 2 (sTNFR-2) in lipodystrophic patients, which was accompanied by loss of subcutaneous fat [16]. TNF- $\alpha$ is a well-known insulin resistance inducer by decreasing insulin receptor kinase activity, prompting apoptosis and lipolysis and also suppressing the expression of insulin receptor kinase substrate (IRS)-1 and GLUT4 [11, 22, 29, 48]. These alterations cause diminished insulin signalling, reduced anti-lipolytic effects of insulin, suppress inhibitory G protein-coupled receptors, reduced activity of lipoprotein lipase and suppression of lipin (a lipid dropletassociated protein which plays a role in protecting adipocytes from hydrolytic action of lipase) [11, 48-50]. IL-6 on the other hand has been shown to alter insulin signalling in adipose tissues, which contributes to insulin resistance [11].

\section{NRTIs and mitochondrial toxicity}

Frequently used tNRTIs (thymidine analogues) have been linked to the pathogenesis of lipoatrophy through mitochondrial toxicity by inhibiting DNA polymerase- $\gamma$, the enzyme that catalyzes mitochondrial DNA (mtDNA) synthesis $[8,11$, $51,52]$. In vitro studies have shown that thymidine analogues cause mitochondrial dysfunction by increasing reactive oxygen species (ROS) and reducing copies of both mtDNA and mtRNA [51, 53]. This disrupts oxidative phosphorylation (OXPHOS) leading to leakage of electrons into the mitochondrial matrix, with concomitant reduction in ATP production [52-54]. Increased ROS in turn binds to cellular macromolecules such as DNA, proteins and lipids and induces adipocyte apoptosis and lipolysis leading to decreased adipocyte density and the lipoatrophic phenotype $[18,53,54]$. It is suggested that cellular and adipose tissue dysfunctions occur mainly when $\mathrm{mtD}$ NA copies fall below critical levels required by mitochondria to generate intracellular ATP [18]. This may be accompanied by increased insulin resistance in the skeletal muscles and adipose tissues as well as hyperlactatemia $[18,51]$.

\section{NNRTIs and metabolic complications}

NNRTIs appear not to induce lipodystrophy or exert any major effects on metabolism $[3,18]$. However, efavirenz has been reported to induce some dyslipidemia in HIV patients by acting synergistically with PIs to decrease lipid storage and downregulate the expression of SREBP-1c, but its contribution to lipodystrophy is not yet fully understood $[3,23,40]$.

\section{Consequences of HAART-Induced Lipodystro- phy}

Patients with HAART-induced lipodystrophy present with loss of subcutaneous fat from buccal, periorbital, temporal regions and extremities $[18,55,56]$. Breast enlargement, visceral fat accumulation (in the abdomen) and dorsocervical fat pads ("buffalo hump") have been observed $[18,23,56]$. These morphological changes are irreversible and non-progressive upon withdrawal of treatment but contribute significantly to social stigma $[13,21]$. Some patients with dorsocervical fat pads have restricted neck mobility, women with breast enlargement may experience chronic back pain, while men with gynecomastia feel socially prejudiced [9]. This may lead to poor adherence to ART, low self-esteem and reduced quality of life in the affected patients $[9,13,21]$. These conditions if not carefully managed may ultimately predispose a significant number of patients to increased risks of metabolic syndrome, diabetes and cardiovascular diseases.

\section{Pharmacological Interventions}

\section{Antiretroviral drug switching}

Ideal treatment regimen should meet therapeutic goals with minimum side-effects and reduced pill burden. More potent and less toxic drugs with simpler dosing schedules and longer half-lives, improved treatment responses and adherence to therapy would be ideal. Fortunately, thymidine analogues though included in HAART as a backbone have long been linked to the development of metabolic complications in the decreasing magnitude in the order of stavudine, zidovudine, didanosine, lamivudine, abacavir and emtricitabine [27, 56]. This has given the clinicians flexibility in making the best combination choices. Consequently, patients who have experienced treatment failures with increases in viral loads, and those who have shown intolerance or presented with metabolic complications, are routinely switched to alternative regiments. In one comparative randomized trial, switching from stavudine to tenofovir other than abacavir showed a significantly greater improvement in TC and LDL-C [57]. Consequently, despite the fact that stavudine has good viral load suppression efficacy, WHO recommended its substitution with tenofovir due to increased propensity to causing peripheral neuropathy, lactic acidosis and lipodystrophy in a significant number of patients [58]. Subsequently, in South African for example, tenofovir is indicated for new patients starting on antiretroviral therapy as well as those who become intolerant to stavudine or zidovudine but those who are not are retained on the same [59].

NNRTIs are generally associated with fewer side-effects and are included in HAART as a base and not used as single agents due to quick emergence of resistance [56]. Currently available NNRTIs include nevirapine, efavirenz, etravirine, and delavir- 
dine with rash as the most commonly shared adverse-effect. Although both nevirapine and efavirenz have significant effects on plasma lipids and effectively suppress viral loads, efavirenz appears to be less associated with common adverse-effects save for central nervous system (CNS) disturbances [3, 60].

Commonly used PIs include saquinavir, lopinavir, darunavir, indinavir, ritonavir, tipranavir, atazanavir, nelfinavir and fosamprenavir. Except for nelfinavir, these PIs are substrates of CYP 3A4 which they also inhibit hence ritonavir which cannot be used at therapeutic doses due to its GI toxicity is included as "booster" at low doses when co-administered with the other PIs to reduce their metabolism, increase plasma concentrations and also reduce pill burden [60]. Commonly used boosted combinations include darunavir/ritonavir and atazanavir/ritonavir, since these newer generation PIs are less associated with metabolic complications compared to their congeners $[3,27,61]$.

\section{Fixed-dose combination therapy}

WHO launched "treatment 2" strategy in 2010 that has since simplified treatment regimens and improved adherence, reduced pill burden, minimized side-effects and the emergence of drug resistance and also reduced treatment costs [61, 62]. This has led to the formulation of single pill regimens containing two NRTIs as the "backbone" and an NNRTI as a "base", substitutable with a boosted PI. Currently, available once-daily fixed-dose combination therapies include tenofovir/emtricitabine/efavirenz as gold standard or tenofovir/emtricitabine/ rilpivirine (for patients who are intolerant to efavirenz), and many others under development $[62,63]$. The components of fixed-dose combinations are carefully selected taking into account pharmacokinetic and therapeutic equivalence profiles of individual drugs to enhance or maintain efficacy at minimum toxicity. With the development of new agents such as entry inhibitors (enfuvirtide and maraviroc), integrase inhibitors such as raltegravir, newer fixed-dose combinations are being formulated to alleviate earlier fears of rigidity in component switching with single pills in vulnerable patients.

However, use of four-drug regimens in treatment naive patients has not been successful owing to failure to improve outcomes and additive adverse-effects of the constituent drugs [64].

\section{New drug developments}

Apart from the ongoing research and development of new drugs with high efficacy and reduced toxicity that could reduce HIV pathogenesis, attempts have also been made to modify the existing drugs to reduce incidences of metabolic disturbances and dyslipidemia associated with their use. Festinavir for example has been developed from stavudine, with less toxicity and used in patients with viral resistance to abacavir and tenofovir $[65,66]$. Similarly, apricitabine, an analogue of cytidine that is structurally related to lamivudine and emtricitabine is currently undergoing clinical trials and has so far been shown to suppress viral replication with less toxicity and is well tolerated [67]. Tenofovir disoproxil fumarate, a prodrug of tenofovir is currently undergoing evaluation to confirm its effects on lipidemia and renal function [68].

Second generation NNRTIs such as etravirine have been developed not only for viral strains that are resistant to nevirapine and efavirenz but also for their efficacy, safety and tolerability [69], although it is not devoid of drug interactions due to its inhibition of CYP 3A4 enzymes [65]. Rilpivirine has similarly been developed to be used in combination with emtricitabine and tenofovir instead of efavirenz and has shown benefits in reducing TC/HDL-C ratio and cardiovascular morbidity $[70,71]$, and is so far promising against NNRTIs resistant strains of HIV-1 [72], as well as many others in different stages of clinical development. Recently, FDA approved cobicistat which inhibits CYP 3A4 enzymes that metabolize raltegravir and elvitegravir, hence acting as a booster to increase their plasma concentrations and is now used in the combination of elvitegravir/cobicistat/tenofovir/emtricitabine as a pharmacokinetic enhancer of elvitegravir [73-76]. It is hoped that these modified versions of existing drugs or pharmacokinetic enhancers will simplify HIV-1 pharmacotherapy and reduce incidences of metabolic complications and lipodystrophy. It should, however, be pointed out that drug switching only leads to partial reversal of lipoatrophy depending on the extent and duration of exposure to HAART [23].

\section{Anti-diabetic agents}

In an effort to contain metabolic syndrome and lipodystrophy, attempts have been made to concurrently administer drugs that are conventionally used as anti-diabetics or anti-dyslipidemics in patients on HAART with controversial outcomes.

\section{Thiazolidinediones}

Thiazolidinediones are PPAR- $\gamma$ agonists used to improve insulin sensitivity by increasing glucose transport, peripheral glucose utilization and adipocyte differentiation [77]. Rosiglitazone and pioglitazone are used for the treatment of type 2 diabetes, due to their effectiveness at increasing adipogenesis which implies that they may reverse subcutaneous fat loss in lipodystrophic patients [78]. However, a recent report by Okada et al has suggested that pioglitazone therapy could increase subcutaneous fat mass in non-lipoatrophic but not in lipoatrophic regions [79] similarly to previous observations that thiazolidinediones do not prevent HAART-associated lipodystrophy [80]. Furthermore, rosiglitazone has recently been linked to the development of adverse cardiovascular events in diabetic patients while pioglitazone is reported to interact with PIs through inhibition of CYP 3 A4 $[8,77,81]$. These observations therefore do suggest that thiazolidinediones may not be effective in the treatment of HAART-associated lipodystrophy after all. Selective modulators of PPAR $-\gamma$ are currently under different stages of clinical development to mimic therapeutic effects of thiozolidinediones with improved side-effects profile. 


\section{Metformin}

Metformin is an insulin-sensitizing agent, used to reduce hepatic gluconeogenesis and to increase glucose uptake by the peripheral tissues [82]. Studies done to monitor the effectiveness of metformin in HAART-treated patients with insulin resistance and lipohypertrophy showed that metformin-treated individuals had significantly improved fasting plasma insulin, decreased body weight and diastolic pressure compared to placebo $[10,83]$. Metformin has also been shown to significantly reduce plasma $\mathrm{TG}$, insulin resistance and improved pancreatic $\beta$-cell function $[84,85]$. These initial hopes have somehow been dimmed by reports that metformin use could be associated with significant loses in subcutaneous adipose tissue (SAT) and viscera adipose tissues (VAT) suggesting deleterious effects of metformin in HAART-treated patients with lipoatrophy [83]. However, metformin impairs oxidative phosphorylation by inhibiting NADH dehydrogenase and DNA pol- $\gamma$ which may hence increase the risk of lactic acidosis when used with NRTIs in diabetic patients [86]. Even though abacavir and tenofovir have the lowest incidence of lactic acidosis of all the other NRTIs, the risk is significantly increased in patients treated concurrently with metformin and tenofovir or in patients with renal insufficiency $[87,88]$. No large-scale clinical trials have, however, been conducted and since tenofovir is an important component of the "backbone" in HAART, use of metformin as adjunct therapy to prevent the development of lipodystrophy syndrome in this category of patients therefore appears to be a remote possibility for now especially in patients with diabetes with or without renal insufficiency.

\section{Anti-dyslipidemic agents}

Statins are hydroxymethylglutaryl coenzyme A (HMG-CoA) reductase inhibitors [47] that reduce plasma cholesterol levels by inhibiting the rate-limiting step of de novo cholesterol synthesis thus reducing plasma TC and LDL-C concentrations, leading to decreased risk of coronary artery events and heart diseases [89-91]. However, the use of simvastatin, pravastatin, fluvastatin or rosuvastatin has been shown to promote reduction of dyslipidemia in patients on HAART to a lesser degree than in seronegative patients [89-91]. Furthermore, most components of HAART as substrates of CYP 3A4 experience significant drug-drug interaction with statins [92]. Simvastatin, lovastatin and atorvastatin are reported to interact with PIs through the inhibition of cytochrome CYP 3A4 leading to increased plasma concentrations of statins and consequently hepatotoxicity, myalgia and rhabdomyolysis [27, 93-97]. Pravastatin, rosuvastatin and fluvastatin are not metabolized by CYP 3A4 hence are less prone to interactions with PIs $[3,65]$ but should be used at the lowest doses possible especially in patients taking darunavir [27]. For the treatment of hypercholesterolemia in patients taking PIs, it has been recommended that pravastatin and/or rosuvastatin be used as first-line while fluvastatin due to its low efficacy reserved as second-line but serum transaminases and creatine kinase levels should be closely monitored [65]. Among NNRTIs, efavirenz has been shown to decrease the plasma area under the curve (AUC) of atorvastatin and simvastatin by $43 \%$ and $58 \%$, respectively $[27,55]$. This suggests that higher doses of atorvastatin and simvastatin are required to lower LDL-C efficiently in patients taking efavirenz [27].

Fibrates are also metabolized by CYP450 isoenzymes, but predominantly through CYP4A pathways, hence the incidence of interaction with PIs is relatively low [98]. Fibrates appear to have significant advantages in HAART patients with hypertriglyceridemia and mixed hyperlipidemia but they do not have same efficacy as statins in preventing cardiovascular disease [65]. Periodic monitoring of serum creatinine kinase and transaminases is suggested in patients on fibrates that are cotreated with statins or fibrates alone due to the increased risk of myopathy [65]. However, no large-scale clinical studies have been conducted to investigate whether liberal incorporation of statins or fibrates into HAART could mitigate the development of lipodystrophy.

Ezetimibe as an inhibitor of intestinal cholesterol absorption has been shown to reduce LDL-C, TC and TG and also increase HDL-C in HIV patients on HAART [99-101]. It is highly tolerable and is devoid of significant drug interactions with HAART [102, 103], hence combination therapy with ezetimibe appears to be superior to pravastatin monotherapy in HAART patients with dyslipidemia [104].

\section{Surgical Interventions}

A recent study in South African reported that $11.7 \%$ of patients on HAART presented with lipodystrophy and that $5.9 \%$ of these would consider non-compliance on the basis of social stigma associated with lipodystrophy, suggesting the need to consider surgical interventions [105]. Surgical techniques used to treat facial lipoatrophy include fat transplantations, facial fillers, facial grafting and injections of synthetic compounds such as poly-lactic acid, polymethyl-methacrylate, silicone, human and bovine collagen [18, 23]. However, facial fillers have been shown to require repeated injections and are associated with granuloma formation $[11,18]$ while facial grafting has been reported to lead to fat resorption after 3 months of surgery [11]. Furthermore, fat transplantation has been shown to be associated with facial fat hypertrophy after a year of surgery $[8,106]$. Using liposuction techniques can be effective in removing fat accumulated in the dorsocervical region ("buffalo hump") in patients with hyperlipotrophy but three of 10 subjects had recurrence of abdominal lipohypertrophy within a year [8, 107]. Despite its cosmetic benefits, plastic surgical interventions are financially beyond the reach of most HIVpositive patients on HAART from a public health perspective. More importantly, despite reducing social stigma, cosmetic surgery does not correct underlying metabolic causes of lipodystrophy in these patients.

\section{Hormone Replacement Therapy}

Hormones that play critical roles in metabolism and energy homeostasis are known to be diminished in patients with 
HAART-associated lipodystrophy. Leptin is a hormone secreted by adipocytes and regulates energy metabolism but the levels are diminished in patients with HAART-associated lipoatrophy and leptin replacement therapy has been shown to decrease central fat mass, improve insulin sensitivity and glucose intolerance [108]. Recombinant human metreleptin has been approved for lipodystrophy but despite being well tolerated, side-effects such as leptin resistance leading to renal impairment and T-cell lymphomas on prolonged use have delayed it approval by FDA pending large-scale well-controlled studies [2, 108, 109]. Androgen deficiency defined by low testosterone levels and hypogonadism is a common feature in HIV-positive men including those on HAART therapy [110112]. However, testosterone supplementation showed reductions in total subcutaneous fat but not visceral abdominal fat in a placebo-controlled random trial suggesting that such effects could not be attributed to HAART-induced lipoatrophy alone [113]. These potential benefits may, however, be negated by the adverse metabolic and endocrine effects, deep-vein thrombosis, gynecomastia and hepatotoxicity after long-term testosterone administration necessitating long-term follow-up [114]. Clinically, testosterone is so far devoid of significant druginteractions with antiretroviral drugs and is formulated for intramuscular, transdermal or buccal administration in patients on HAART depending on their preferences, tolerability and adherence [115-118]. Oral synthetic analogues of testosterone such as oxandrolone and oxymetholone are similarly devoid of drug-interactions with antiretrovirals and may be preferred to injectable testosterone [119-122] but their therapeutic effects appear to be more significant in HIV-wasting than reversing HAART-associated lipodystrophy.

\section{Growth Factors and Cytokines}

Before the advent of HAART, HIV-positive patients presented with a wasting syndrome characterized by loss of skeletal muscle mass, strength and function due to resistance to growth hormone anabolic effects and its reduced plasma concentrations [123, 124]. Consequently, administration of high doses of recombinant human growth hormone (rhGH) at high doses to HIV-positive patients with wasting syndrome was noted to increase skeletal muscle and bone masses and also decreased body fat accumulation, but at the same time caused insulin resistance, glucose intolerance and tunnel syndrome whereas dose reductions were associated with only modest efficacy and reduced side-effects [123, 124]. Unfortunately, these beneficial effects of rhGH waned with cessation of therapy and the body composition reverted to baseline [8]. Furthermore, somatropin, an rhGH was shown to induce CYP 3A4 and significantly interact with HAART components besides increased side-effects such as edema, musculoskeletal pain, gynecomastia, insulin resistance and impaired glucose tolerance which limited its therapeutic potential $[115,125-129]$. Consequently, rhGH releasing hormone analogues such as tesamorelin, which augment GH pulsatility and preserve negative feedback inhibition of insulin-like growth factor-1 (IGF-1) have been developed [8]. Unlike other growth hormone releasing hormones, tesa- morelin has been shown to be resistant to dipeptidyl aminopeptidase 4 (DPP-4) degradation, increases plasma GH and IGF-1 concentrations, improves lipid profile by reducing trunk (but not extremity) fat and VAT, TG and TC/HDL-C ratios in random placebo-controlled clinical trials [8, 130, 131]. However, despite its significance in reducing VAT in patients with lipodystrophy, tesamorelin effects appear not to be sustainable upon discontinuation of therapy. This suggests a need for chronic administration which may be associated with increased risks of diabetes (due to raised IGF-1 levels), persistently activated $\mathrm{GH}$ axis which may be associated with increased risks of pituitary hyperplasia or adenoma and decreased cardiovascular disease risks [131, 132]. Additionally patients on tesamorelin therapy have been noted to develop anti-tesamorelin antibodies although clinical implications of this are currently not fully understood [132]. In addition to these concerns, GH and its analogues are expensive and may be not affordable to many patients.

A study has suggested that IGF-1 complexed to its major binding protein-3 (IGFBP-3) to increase its half-life is associated with improved glucose tolerance and insulin resistance but not visceral adiposity [133] but this may increase plasma IGF-1 concentrations and its deleterious effects on glucose tolerance hence may not benefit the patients after all.

TNF- $\alpha$ has been associated with lipoatrophy in patients treated with NRTIs as it promotes adipocyte apoptosis [134]. TNF- $\alpha$ antagonist thalidomide has hence been shown to be effective in HIV-1 wasting syndrome [135], but the potential benefits are negated by its known toxicity and may not be a viable option.

\section{Lifestyle Modifications}

\section{Exercise}

Lifestyle interventions such as exercise and diet as first-line interventions may be useful alternatives in the management of HAART-induced lipodystrophy due to their safety and tolerability [11]. HIV-positive individuals who were subjected to supervised exercise training program showed decreased total adipose tissue, enhanced skeletal muscle strength and endurance, cardiorespiratory fitness, and reduced waist circumference (but with no changes in VAT), increased insulin-mediated glucose uptake and insulin sensitivity $[8,136]$. Exercise therefore appears to have beneficial effects on lipid profiles and central fat accumulation in HAART-associated lipodystrophy [136] though the outcomes are still controversial $[137,138]$.

\section{Nutritional therapy}

Limited information is currently available on the effects of diet on HAART-associated lipodystrophy and metabolic abnormalities [11]. Barrios et al have shown that adherence to low-fat diet for 6 months decreased total cholesterol by $10 \%$ and $\mathrm{TG}$ by $23 \%$ in HIV-infected adults with hyperlipidemia [139] contrary to the findings of a small scale pilot study of $\mathrm{Ng}$ et al that 
showed significantly increased plasma concentrations of cholesterol but with no change in TG concentrations after 9 - 12 months in lipodystrophic patients exposed to modified Mediterranean diets [140]. It has been suggested that a combination of moderate-fat, high fiber diet and exercise could decrease LDL-C, fasting glucose and insulin resistance in male subjects with lipodystrophy [141] and also that low-fat diet and aerobic exercise could reduce central adiposity and waist/hip ratio in HIV patients with lipodystrophy [137].

Nutritional supplements such as L-acetylcarnitine, uridine and niacin have been shown to improve lipid profile in HAART-treated lipodystrophy patients [11]. Patients who received $4 \mathrm{~g} / \mathrm{d}$ of L-acetylcarnitine for 1 year showed increased rates of lipid oxidation, decreased mass of intramyocellular TG and modest effects on insulin sensitivity compared to controls after 8 months [142]. Uridine has been shown to repeal mitochondrial toxicity in adipocytes and hepatocytes exposed to stavudine and zidovudine but not didanosine in vitro and also prevent the effects of zalcitabine on mitochondrial function in HepG2 cells with respect to lactate synthesis, hepatocyte proliferation, intracellular lipids and cyclooxygenase-2 levels $[143,144]$. Furthermore, uridine supplementation may prevent mtDNA damage and adipocyte apoptosis resulting in increased limb fat mass in lipoatrophic adults who were on tNRTI therapy without loss of efficacy [144, 145].

Niacin is known to control lipoprotein metabolism and suppress synthesis of TG and patients treated with low-fat diet, exercise and niacin had significantly increased plasma concentrations of HDL-C and TC compared to the controls after 24 weeks [146, 147]. However, niacin appeared to increase the risk of insulin resistance in HIV patients [146]. A Brazilian cross-sectional study established that HIV patients who consumed two servings dairy food each day had significantly low BMI, waist circumference and blood pressure than those who consumed lesser amounts implicating high calcium intake in these changes though polyunsaturated fat was associated with insulin resistance [148]. Nevertheless, other studies have shown no effect on fasting insulin, insulin resistance, total HDL, TAG and cholesterol or a decrease concentration of adiponectin in HIV-positive individuals [64] or a relationship between nutrient intake and visceral adiposity [149].

Diet and exercise are relatively safe and typically well tolerated; hence they can be commended as the first-line interventions in the management of lipohypertrophy to mitigate development of cardiovascular morbidity [3]. These interventions are as recommended for HAART patients as for the general population and the intake of saturated fats should be restricted to $<7 \%$ of total calorie intake and cholesterol intake to $<200$ $\mathrm{mg} /$ day [65] to delay the need for lipid-lowering therapy. Fish oils which are rich in omega-3 fatty acids (eicosapentaenoic and docosahexaenoic acids) are recommended to reduce TG concentrations and hence the risk of atherogenic cardiovascular disease [150-153].

\section{Anti-oxidants as nutritional supplements}

A negative association has been reported between total and supplemental vitamin E intake and diastolic pressure in HIV-pos- itive individuals [154]. Reduced plasma vitamin E concentrations have recently been demonstrated in patients treated with NRTI compared to NNRTIs or PIs suggesting a link between oxidative stress and HAART [155]. HIV-1 infection alone or in combination with HAART has been suggested to induce oxidative stress by impairing anti-oxidant enzymes functions [156]. We have recently reported that grapefruit-derived flavonoid, naringin, prevents stavudine- or zidovudine-induced oxidative stress, hepatocyte apoptosis and mitochondrial toxicity in experimental animals [157, 158]. Although these findings are yet to be corroborated by large-scale clinical trials, clearly our findings provide evidence for anti-oxidant supplementation in patients on HAART as alternatives for non-infective co-morbidities in HIV patients.

\section{Clinical Perspectives}

In the advent of HAART, patients diagnosed with HIV are initiated on treatment as soon CD4 cell counts fall below 500 cells $/ \mu \mathrm{L}$ [159], meaning that treatment commences early before the patient presents with HIV wasting syndrome. Furthermore, with intensive HAART, metabolic complications that the patients are likely to encounter are treatment-related and not due to viral pathogenesis which is largely suppressed. Although it is evident that risk factors for the development of lipodystrophy in patients on HAART include older age, white race, lower BMI, higher viral loads, lower nadir $\mathrm{CD}^{+}{ }^{+} \mathrm{T}$-cell counts at the initiation of therapy, longer duration of exposure HAART [160-164], genetics also play apart [165-167]. Treatment of lipodystrophy in patients on HAART should therefore be largely tailor-made taking into account the patient's presentation and socio-economic status from a public health perspective. With the development of new drugs and modified versions of the older ones, prevalence of HAART-associated lipodystrophy is expected to decline in the not so distant future. Flexibility of drug switching for example has led to the replacement of stavudine with tenofovir in the HAART backbone due to lactic acidosis and other metabolic complications despite its superior viral load suppressing potency $[57,58]$. In the HAART base, efavirenz appears to be safer compared to nevirapine $[3,60]$ while boosted (with ritonavir) atazanavir or darunavir appears to be relatively safer among the PIs [61]. The development of fixed-dose combinations has improved patient compliance and treatment outcomes. New agents coming into the market such as fusion or integrase inhibitors are expected to simplify treatment protocol, with less side-effects and reduced drug-interactions. Adjunct therapy with anti-diabetic, anti-dyslipidemic agents should be avoided if possible due to aforementioned consequences. Surgical interventions, hormone replacement therapy or treatment with cytokines and growth factors may not be affordable to many patients and do not offer permanent solutions to lipodystrophy. Preventative therapy as suggested in Table 1 should perhaps be considered if the long-term consequences of lipodystrophy in patients on HAART are to be avoided. Moderate exercise and dietary manipulations should be commenced as soon as patients are initiated on HAART. Nutritional supplementation with diets rich in 
Table 1. Conservative Therapeutic Strategies for the Management of HAART-Induced Lipodystrophy

\begin{tabular}{|c|c|c|c|}
\hline Presentation & Features & Common causes & Suggested interventions \\
\hline \multicolumn{4}{|l|}{ Lipodystrophy } \\
\hline Lipoatrophy & $\begin{array}{l}\text { Loss of subcutaneous fat } \\
\text { from buccal, periorbital, } \\
\text { temporal regions and } \\
\text { extremities }\end{array}$ & $\begin{array}{l}\text { NRTIs: Stavudine }> \\
\text { zidovudine }>\text { didanosine } \\
>\text { lamivudine in } \\
\text { decreasing order of } \\
\text { magnitude }\end{array}$ & $\begin{array}{l}\text { 1. Switch from stavudine or zidovudine to tenofovir or } \\
\text { abacavir. Consider new generation NRTIs devoid of } \\
\text { adverse-effects. } \\
\text { 2. Nutritional therapy: increased dietary flavonoids intake } \\
\text { 3. Moderate exercise but may worsen subcutaneous fat loss }\end{array}$ \\
\hline \multicolumn{4}{|l|}{ Glucose intolerance } \\
\hline Impaired FBG & $\mathrm{FBG}>6.0 \mathrm{mM}$ & $\begin{array}{l}\text { PIs: Indinavir, } \\
\text { saquinavir, nelfinavir, } \\
\text { lopinavir } \\
\text { NRTIs: stavudine, } \\
\text { zidovudine, lamivudine }\end{array}$ & $\begin{array}{l}\text { 1. Switch to ritonavir boosted atazanavir or darunavir } \\
\text { 2. Avoid stavudine, zidovudine, lamivudine } \\
\text { 3. Nutritional therapy } \\
\text { 4. Moderate exercise }\end{array}$ \\
\hline IR & Elevated FPI & $\begin{array}{l}\text { PIs: Indinavir, } \\
\text { saquinavir, nelfinavir }\end{array}$ & $\begin{array}{l}\text { 1. Switch to ritonavir boosted atazanavir or darunavir } \\
\text { 2. Nutritional therapy } \\
\text { 3. Moderate exercise }\end{array}$ \\
\hline $\mathrm{T} 2 \mathrm{D}$ & $\begin{array}{l}\text { Overt hyperglycemia } \\
\text { without metabolic } \\
\text { complications }\end{array}$ & $\begin{array}{l}\text { PIs: Indinavir, } \\
\text { saquinavir, nelfinavir }\end{array}$ & $\begin{array}{l}\text { 1. Nutritional therapy } \\
\text { 2. Moderate exercise } \\
\text { 3. GLP-1 analogues (avoid metformin) in obese patients } \\
\text { 4. Oral hypoglycemics }\end{array}$ \\
\hline
\end{tabular}

FBG: fasting blood glucose; IR: insulin resistance; FPI: fasting plasma insulin.

flavonoids should be considered for patients on HAART.

\section{Conflicts of Interest}

None.

\section{References}

1. Shenoy A, Ramapuram JT, Unnikrishan B, Achappa B, Madi D, Rao S, Mahalingam S. Effect of Lipodystrophy on the Quality of Life among People Living with HIV (PLHIV) on Highly Active Antiretroviral Therapy. J Int Assoc Provid AIDS Care. 2014;13(5):471-475.

2. Paruthi J, Gill N, Mantzoros CS. Adipokines in the HIV/ HAART-associated lipodystrophy syndrome. Metabolism. 2013;62(9):1199-1205.

3. Feeney ER, Mallon PW. HIV and HAART-Associated Dyslipidemia. Open Cardiovasc Med J. 2011;5:49-63.

4. Kis O, Robillard K, Chan GN, Bendayan R. The complexities of antiretroviral drug-drug interactions: role of $\mathrm{ABC}$ and SLC transporters. Trends Pharmacol Sci. 2010;31(1):22-35.

5. Fisher SD, Miller TL, Lipshultz SE. Impact of HIV and highly active antiretroviral therapy on leukocyte adhesion molecules, arterial inflammation, dyslipidemia, and atherosclerosis. Atherosclerosis. 2006;185(1):1-11.
6. Souza SJ, Luzia LA, Santos SS, Rondo PH. Lipid profile of HIV-infected patients in relation to antiretroviral therapy: a review. Rev Assoc Med Bras (1992). 2013;59(2):186-198.

7. Vu CN, Ruiz-Esponda R, Yang E, Chang E, Gillard B, Pownall HJ, Hoogeveen RC, et al. Altered relationship of plasma triglycerides to HDL cholesterol in patients with HIV/HAART-associated dyslipidemia: further evidence for a unique form of metabolic syndrome in HIV patients. Metabolism. 2013;62(7):1014-1020.

8. Leung VL, Glesby MJ. Pathogenesis and treatment of HIV lipohypertrophy. Curr Opin Infect Dis. 2011;24(1):43-49.

9. Bonnet E. New and emerging agents in the management of lipodystrophy in HIV-infected patients. HIV AIDS (Auckl). 2010;2:167-178.

10. Leow MK, Addy CL, Mantzoros CS. Clinical review 159: Human immunodeficiency virus/highly active antiretroviral therapy-associated metabolic syndrome: clinical presentation, pathophysiology, and therapeutic strategies. J Clin Endocrinol Metab. 2003;88(5):1961-1976.

11. Loonam CR, Mullen A. Nutrition and the HIV-associated lipodystrophy syndrome. Nutr Res Rev. 2012;25(2):267287.

12. Reust CE. Common adverse effects of antiretroviral therapy for HIV disease. Am Fam Physician. 2011;83(12):1443-1451.

13. Guaraldi G, Orlando G, De Fazio D, De Lorenzi I, Rottino A, De Santis G, Pedone A, et al. Comparison of three 
different interventions for the correction of HIV-associated facial lipoatrophy: a prospective study. Antivir Ther. 2005;10(6):753-759.

14. Carr A, Cooper DA. Adverse effects of antiretroviral therapy. Lancet. 2000;356(9239):1423-1430.

15. Carr A. HIV protease inhibitor-related lipodystrophy syndrome. Clin Infect Dis. 2000;30(Suppl 2):S135-142.

16. Mynarcik DC, McNurlan MA, Steigbigel RT, Fuhrer J, Gelato MC. Association of severe insulin resistance with both loss of limb fat and elevated serum tumor necrosis factor receptor levels in HIV lipodystrophy. J Acquir Immune Defic Syndr. 2000;25(4):312-321.

17. Carr A, Samaras K, Burton S, Law M, Freund J, Chisholm DJ, Cooper DA. A syndrome of peripheral lipodystrophy, hyperlipidaemia and insulin resistance in patients receiving HIV protease inhibitors. AIDS. 1998;12(7):F51-58.

18. Waters L, Nelson M. Long-term complications of antiretroviral therapy: lipoatrophy. Int J Clin Pract. 2007;61(6):999-1014.

19. Anuurad E, Semrad A, Berglund L. Human immunodeficiency virus and highly active antiretroviral therapy-associated metabolic disorders and risk factors for cardiovascular disease. Metab Syndr Relat Disord. 2009; 7(5):401-410.

20. Anuurad E, Bremer A, Berglund L. HIV protease inhibitors and obesity. Curr Opin Endocrinol Diabetes Obes. 2010;17(5):478-485.

21. Pirmohamed M. Clinical management of HIV-associated lipodystrophy. Curr Opin Lipidol. 2009;20(4):309-314.

22. Carper MJ, Cade WT, Cam M, Zhang S, Shalev A, Yarasheski KE, Ramanadham S. HIV-protease inhibitors induce expression of suppressor of cytokine signaling-1 in insulin-sensitive tissues and promote insulin resistance and type 2 diabetes mellitus. Am J Physiol Endocrinol Metab. 2008;294(3):E558-567.

23. Singhania R, Kotler DP. Lipodystrophy in HIV patients: its challenges and management approaches. HIV AIDS (Auckl). 2011;3:135-143.

24. Tsiodras S, Perelas A, Wanke C, Mantzoros CS. The HIV-1/HAART associated metabolic syndrome - novel adipokines, molecular associations and therapeutic implications. J Infect. 2010;61(2):101-113.

25. Dau B, Holodniy M. The Relationship Between HIV Infection and Cardiovascular Disease. Curr Cardiol Rev. 2008;4(3):203-218.

26. James J, Carruthers A, Carruthers J. HIV-associated facial lipoatrophy. Dermatol Surg. 2002;28(11):979-986.

27. Aberg JA. Lipid management in patients who have HIV and are receiving HIV therapy. Endocrinol Metab Clin North Am. 2009;38(1):207-222.

28. Estrada V, Portilla J. Dyslipidemia related to antiretroviral therapy. AIDS Rev. 2011;13(1):49-56.

29. Flint OP, Noor MA, Hruz PW, Hylemon PB, Yarasheski K, Kotler DP, Parker RA, et al. The role of protease inhibitors in the pathogenesis of HIV-associated lipodystrophy: cellular mechanisms and clinical implications. Toxicol Pathol. 2009;37(1):65-77.

30. Vigouroux C, Maachi M, Nguyen TH, Coussieu C, Gharakhanian S, Funahashi T, Matsuzawa Y, et al. Serum adipocytokines are related to lipodystrophy and metabolic disorders in HIV-infected men under antiretroviral therapy. AIDS. 2003;17(10):1503-1511.

31. Wunder D, Bersinger NA, Fux C, Weber R, Bernasconi E, Cavassini M, Bucher HC, et al. Plasma leptin levels in men are not related to the development of lipoatrophy during antiretroviral therapy. AIDS. 2005;19(16):18371842.

32. Fiorenza CG, Chou SH, Mantzoros CS. Lipodystrophy: pathophysiology and advances in treatment. Nat Rev Endocrinol. 2011;7(3):137-150.

33. Friis-Moller N, Weber R, Reiss P, Thiebaut R, Kirk O, d'Arminio Monforte A, Pradier C, et al. Cardiovascular disease risk factors in HIV patients - association with antiretroviral therapy. Results from the DAD study. AIDS. 2003;17(8):1179-1193.

34. Dolan SE, Hadigan C, Killilea KM, Sullivan MP, Hemphill L, Lees RS, Schoenfeld D, et al. Increased cardiovascular disease risk indices in HIV-infected women. J Acquir Immune Defic Syndr. 2005;39(1):44-54.

35. Leitner JM, Pernerstorfer-Schoen H, Weiss A, Schindler K, Rieger A, Jilma B. Age and sex modulate metabolic and cardiovascular risk markers of patients after 1 year of highly active antiretroviral therapy (HAART). Atherosclerosis. 2006;187(1):177-185.

36. Marso SP, Mehta SK, Frutkin A, House JA, McCrary JR, Kulkarni KR. Low adiponectin levels are associated with atherogenic dyslipidemia and lipid-rich plaque in nondiabetic coronary arteries. Diabetes Care. 2008;31(5):989994.

37. Schindler K, Haider D, Wolzt M, Rieger A, Gmeinhart B, Luger A, Nowotny $\mathrm{P}$, et al. Impact of antiretroviral therapy on visfatin and retinol-binding protein 4 in HIVinfected subjects. Eur J Clin Invest. 2006;36(9):640-646.

38. Bastard JP, Caron M, Vidal H, Jan V, Auclair M, Vigouroux C, Luboinski J, et al. Association between altered expression of adipogenic factor SREBP1 in lipoatrophic adipose tissue from HIV-1-infected patients and abnormal adipocyte differentiation and insulin resistance. Lancet. 2002;359(9311):1026-1031.

39. Jones SP, Waitt C, Sutton R, Back DJ, Pirmohamed M. Effect of atazanavir and ritonavir on the differentiation and adipokine secretion of human subcutaneous and omental preadipocytes. AIDS. 2008;22(11):1293-1298.

40. Kumarasamy N, Solomon S, Flanigan TP, Hemalatha R, Thyagarajan SP, Mayer KH. Natural history of human immunodeficiency virus disease in southern India. Clin Infect Dis. 2003;36(1):79-85.

41. Steppan CM, Bailey ST, Bhat S, Brown EJ, Banerjee RR, Wright CM, Patel HR, et al. The hormone resistin links obesity to diabetes. Nature. 2001;409(6818):307-312.

42. Chen CC, Li TC, Li CI, Liu CS, Wang HJ, Lin CC. Serum resistin level among healthy subjects: relationship to anthropometric and metabolic parameters. Metabolism. 2005;54(4):471-475.

43. Utzschneider KM, Carr DB, Tong J, Wallace TM, Hull RL, Zraika S, Xiao Q, et al. Resistin is not associated with insulin sensitivity or the metabolic syndrome in humans. Diabetologia. 2005;48(11):2330-2333. 
44. Barb D, Wadhwa SG, Kratzsch J, Gavrila A, Chan JL, Williams CJ, Karchmer AW, et al. Circulating resistin levels are not associated with fat redistribution, insulin resistance, or metabolic profile in patients with the highly active antiretroviral therapy-induced metabolic syndrome. J Clin Endocrinol Metab. 2005;90(9):5324-5328.

45. Ranade K, Geese WJ, Noor M, Flint O, Tebas P, Mulligan $\mathrm{K}$, Powderly W, et al. Genetic analysis implicates resistin in HIV lipodystrophy. AIDS. 2008;22(13):1561-1568.

46. Masia M, Padilla S, Garcia N, Jarrin I, Bernal E, Lopez $\mathrm{N}$, Hernandez I, et al. Endothelial function is impaired in HIV-infected patients with lipodystrophy. Antivir Ther. 2010;15(1):101-110.

47. Crawford KW, Li X, Xu X, Abraham AG, Dobs AS, Margolick JB, Palella FJ, et al. Lipodystrophy and inflammation predict later grip strength in HIV-infected men: the MACS Body Composition substudy. AIDS Res Hum Retroviruses. 2013;29(8):1138-1145.

48. Domingo P, Vidal F, Domingo JC, Veloso S, Sambeat MA, Torres F, Sirvent JJ, et al. Tumour necrosis factor alpha in fat redistribution syndromes associated with combination antiretroviral therapy in HIV-1-infected patients: potential role in subcutaneous adipocyte apoptosis. Eur J Clin Invest. 2005;35(12):771-780.

49. Rudich A, Ben-Romano R, Etzion S, Bashan N. Cellular mechanisms of insulin resistance, lipodystrophy and atherosclerosis induced by HIV protease inhibitors. Acta Physiol Scand. 2005;183(1):75-88.

50. Zhang HH, Halbleib M, Ahmad F, Manganiello VC, Greenberg AS. Tumor necrosis factor-alpha stimulates lipolysis in differentiated human adipocytes through activation of extracellular signal-related kinase and elevation of intracellular cAMP. Diabetes. 2002;51(10):2929-2935.

51. Apostolova N, Blas-Garcia A, Esplugues JV. Mitochondrial interference by anti-HIV drugs: mechanisms beyond Pol-gamma inhibition. Trends Pharmacol Sci. 2011;32(12):715-725.

52. Dragovic G, Jevtovic D. The role of nucleoside reverse transcriptase inhibitors usage in the incidence of hyperlactatemia and lactic acidosis in HIV/AIDS patients. Biomed Pharmacother. 2012;66(4):308-311.

53. Saitoh A, Haas RH, Naviaux RK, Salva NG, Wong JK, Spector SA. Impact of nucleoside reverse transcriptase inhibitors on mitochondrial DNA and RNA in human skeletal muscle cells. Antimicrob Agents Chemother. 2008;52(8):2825-2830.

54. Kotler DP. HIV and antiretroviral therapy: lipid abnormalities and associated cardiovascular risk in HIV-infected patients. J Acquir Immune Defic Syndr. 2008;49(Suppl 2):S79-85.

55. Troll JG. Approach to dyslipidemia, lipodystrophy, and cardiovascular risk in patients with HIV infection. Curr Atheroscler Rep. 2011;13(1):51-56.

56. Palios J, Kadoglou NP, Lampropoulos S. The pathophysiology of HIV-/HAART-related metabolic syndrome leading to cardiovascular disorders: the emerging role of adipokines. Exp Diabetes Res. 2012;2012:103063.

57. Moyle GJ, Sabin CA, Cartledge J, Johnson M, Wilkins E, Churchill D, Hay $\mathrm{P}$, et al. A randomized comparative trial of tenofovir DF or abacavir as replacement for a thymidine analogue in persons with lipoatrophy. AIDS. 2006;20(16):2043-2050.

58. World Health Organisation. Antiretroviral therapy for HIV infection in adults and adolescents. Geneva: World Health Organisation. 2010.

59. Njuguna C, Orrell C, Kaplan R, Bekker LG, Wood R, Lawn SD. Rates of switching antiretroviral drugs in a primary care service in South Africa before and after introduction of tenofovir. PLoS One. 2013;8(5):e63596.

60. Coovadia A, Abrams EJ, Strehlau R, Shiau S, Pinillos F, Martens L, Patel F, et al. Efavirenz-Based Antiretroviral Therapy Among Nevirapine-Exposed HIV-Infected Children in South Africa: A Randomized Clinical Trial. JAMA. 2015;314(17):1808-1817.

61. Duncombe C, Ball A, Passarelli C, Hirnschall G. Treatment 2.0: catalyzing the next phase of treatment, care and support. Curr Opin HIV AIDS. 2013;8(1):4-11.

62. Ford N, Flexner C, Vella S, Ripin D, Vitoria M. Optimization and simplification of antiretroviral therapy for adults and children. Curr Opin HIV AIDS. 2013;8(6):591-599.

63. Llibre JM, Clotet B. Once-daily single-tablet regimens: a long and winding road to excellence in antiretroviral treatment. AIDS Rev. 2012;14(3):168-178.

64. Shafer RW, Smeaton LM, Robbins GK, De Gruttola V, Snyder SW, D'Aquila RT, Johnson VA, et al. Comparison of four-drug regimens and pairs of sequential three-drug regimens as initial therapy for HIV-1 infection. N Engl J Med. 2003;349(24):2304-2315.

65. da Cunha J, Maselli LM, Stern AC, Spada C, Bydlowski SP. Impact of antiretroviral therapy on lipid metabolism of human immunodeficiency virus-infected patients: Old and new drugs. World J Virol. 2015;4(2):56-77.

66. Haraguchi K, Takeda S, Kubota Y, Kumamoto H, Tanaka H, Hamasaki T, Baba M, et al. From the chemistry of epoxy-sugar nucleosides to the discovery of anti-HIV agent 4'-ethynylstavudine-Festinavir. Curr Pharm Des. 2013;19(10):1880-1897.

67. Cahn P, Altclas J, Martins M, Losso M, Cassetti I, Cooper DA, Cox S. Antiviral activity of apricitabine in treatmentexperienced HIV-1-infected patients with M184V who are failing combination therapy. HIV Med. 2011;12(6):334342.

68. Markowitz M, Zolopa A, Squires K, Ruane P, Coakley D, Kearney B, Zhong L, et al. Phase I/II study of the pharmacokinetics, safety and antiretroviral activity of tenofovir alafenamide, a new prodrug of the HIV reverse transcriptase inhibitor tenofovir, in HIV-infected adults. J Antimicrob Chemother. 2014;69(5):1362-1369.

69. Vingerhoets J, Azijn H, Fransen E, De Baere I, Smeulders L, Jochmans D, Andries K, et al. TMC125 displays a high genetic barrier to the development of resistance: evidence from in vitro selection experiments. J Virol. 2005;79(20):12773-12782.

70. Goebel F, Yakovlev A, Pozniak AL, Vinogradova E, Boogaerts G, Hoetelmans R, de Bethune MP, et al. Short-term antiviral activity of TMC278 - a novel NNRTI - in treatment-naive HIV-1-infected subjects. AIDS. 2006;20(13):1721-1726. 
71. Tebas P, Sension M, Arribas J, Duiculescu D, Florence E, Hung CC, Wilkin T, et al. Lipid levels and changes in body fat distribution in treatment-naive, HIV-1-Infected adults treated with rilpivirine or Efavirenz for 96 weeks in the ECHO and THRIVE trials. Clin Infect Dis. 2014;59(3):425-434.

72. Cote B, Burch JD, Asante-Appiah E, Bayly C, Bedard L, Blouin M, Campeau LC, et al. Discovery of MK-1439, an orally bioavailable non-nucleoside reverse transcriptase inhibitor potent against a wide range of resistant mutant HIV viruses. Bioorg Med Chem Lett. 2014;24(3):917922.

73. Nathan B, Bayley J, Waters L, Post FA. Cobicistat: a Novel Pharmacoenhancer for Co-Formulation with HIV Protease and Integrase Inhibitors. Infect Dis Ther. 2013;2(2):111-122.

74. Lepist EI, Phan TK, Roy A, Tong L, Maclennan K, Murray $\mathrm{B}$, Ray AS. Cobicistat boosts the intestinal absorption of transport substrates, including HIV protease inhibitors and GS-7340, in vitro. Antimicrob Agents Chemother. 2012;56(10):5409-5413.

75. Sax PE, Wohl D, Yin MT, Post F, DeJesus E, Saag M, Pozniak A, et al. Tenofovir alafenamide versus tenofovir disoproxil fumarate, coformulated with elvitegravir, cobicistat, and emtricitabine, for initial treatment of HIV-1 infection: two randomised, double-blind, phase 3, noninferiority trials. Lancet. 2015;385(9987):2606-2615.

76. Sax PE, DeJesus E, Mills A, Zolopa A, Cohen C, Wohl D, Gallant JE, et al. Co-formulated elvitegravir, cobicistat, emtricitabine, and tenofovir versus co-formulated efavirenz, emtricitabine, and tenofovir for initial treatment of HIV-1 infection: a randomised, double-blind, phase 3 trial, analysis of results after 48 weeks. Lancet. 2012;379(9835):2439-2448.

77. Sutinen J. The effects of Thiazolidinediones on metabolic complications and Lipodystrophy in HIV-infected patients. PPAR Res. 2009;2009:373524.

78. Edgeworth A, Treacy MP, Hurst TP. Thiazolidinediones in the treatment of HIV/HAART-associated lipodystrophy syndrome. AIDS Rev. 2013;15(3):171-180.

79. Okada S, Konishi M, Ishii H. Pioglitazone therapy for HIV/HAART-associated lipodystrophy syndrome could increase subcutaneous fat mass in non-lipoatrophic but not in lipoatrophic regions. BMJ Case Rep. 2016;2016.

80. Blumer RM, van der Valk M, Ackermans M, Endert E, Serlie MJ, Reiss P, Sauerwein HP. A rosiglitazone-induced increase in adiponectin does not improve glucose metabolism in HIV-infected patients with overt lipoatrophy. Am J Physiol Endocrinol Metab. 2009;297(5):E1097-1104.

81. Nissen SE, Wolski K. Effect of rosiglitazone on the risk of myocardial infarction and death from cardiovascular causes. N Engl J Med. 2007;356(24):2457-2471.

82. van Wijk JP, Hoepelman AI, de Koning EJ, DallingaThie G, Rabelink TJ, Cabezas MC. Differential effects of rosiglitazone and metformin on postprandial lipemia in patients with HIV-lipodystrophy. Arterioscler Thromb Vasc Biol. 2011;31(1):228-233.

83. Kohli R, Shevitz A, Gorbach S, Wanke C. A randomized placebo-controlled trial of metformin for the treatment of
HIV lipodystrophy. HIV Med. 2007;8(7):420-426.

84. Tomazic J, Karner P, Vidmar L, Maticic M, Sharma PM, Janez A. Effect of metformin and rosiglitazone on lipid metabolism in HIV infected patients receiving protease inhibitor containing HAART. Acta Dermatovenerol Alp Pannonica Adriat. 2005;14(3):99-105.

85. Silic A, Janez A, Tomazic J, Karner P, Vidmar L, Sharma $\mathrm{P}$, Maticic M. Effect of rosiglitazone and metformin on insulin resistance in patients infected with human immunodeficiency virus receiving highly active antiretroviral therapy containing protease inhibitor: randomized prospective controlled clinical trial. Croat Med J. 2007;48(6):791-799.

86. Ortiz-Brizuela E, Perez-Patrigeon S, Recillas-Gispert C, Gomez-Perez FJ. Lactic Acidosis Complicating Metformin and Non-Nucleoside Reverse Transcriptase Inhibitor Combination Therapy: A Smoldering Threat in the Post-HAART Era. Rev Invest Clin. 2015;67(4):273-274.

87. Worth L, Elliott J, Anderson J, Sasadeusz J, Street A, Lewin S. A cautionary tale: fatal lactic acidosis complicating nucleoside analogue and metformin therapy. Clin Infect Dis. 2003;37(2):315-316.

88. Aperis G, Paliouras C, Zervos A, Arvanitis A, Alivanis P. Lactic acidosis after concomitant treatment with metformin and tenofovir in a patient with HIV infection. J Ren Care. 2011;37(1):25-29.

89. Baigent C, Keech A, Kearney PM, Blackwell L, Buck G, Pollicino C, Kirby A, et al. Efficacy and safety of cholesterol-lowering treatment: prospective meta-analysis of data from 90,056 participants in 14 randomised trials of statins. Lancet. 2005;366(9493):1267-1278.

90. Boccara F, Simon T, Lacombe K, Cohen A, Laloux B, Bozec E, Durant S, et al. Influence of pravastatin on carotid artery structure and function in dyslipidemic HIVinfected patients receiving antiretroviral therapy. AIDS. 2006;20(18):2395-2398.

91. Stein JH, Merwood MA, Bellehumeur JL, Aeschlimann SE, Korcarz CE, Underbakke GL, Mays ME, et al. Effects of pravastatin on lipoproteins and endothelial function in patients receiving human immunodeficiency virus protease inhibitors. Am Heart J. 2004;147(4):E18.

92. Calza L, Colangeli V, Manfredi R, Legnani G, Tampellini L, Pocaterra D, Chiodo F. Rosuvastatin for the treatment of hyperlipidaemia in HIV-infected patients receiving protease inhibitors: a pilot study. AIDS. 2005;19(10):11031105.

93. Fichtenbaum CJ, Gerber JG, Rosenkranz SL, Segal Y, Aberg JA, Blaschke T, Alston B, et al. Pharmacokinetic interactions between protease inhibitors and statins in HIV seronegative volunteers: ACTG Study A5047. AIDS. 2002;16(4):569-577.

94. Fichtenbaum CJ, Gerber JG. Interactions between antiretroviral drugs and drugs used for the therapy of the metabolic complications encountered during HIV infection. Clin Pharmacokinet. 2002;41(14):1195-1211.

95. Williams D, Feely J. Pharmacokinetic-pharmacodynamic drug interactions with $\mathrm{HMG}-\mathrm{CoA}$ reductase inhibitors. Clin Pharmacokinet. 2002;41(5):343-370.

96. Hare CB, Vu MP, Grunfeld C, Lampiris HW. Simvasta- 
tin-nelfinavir interaction implicated in rhabdomyolysis and death. Clin Infect Dis. 2002;35(10):e111-112.

97. Moro H, Tsukada H, Tanuma A, Shirasaki A, Iino N, Nishibori T, Nishi S, et al. Rhabdomyolysis after simvastatin therapy in an HIV-infected patient with chronic renal failure. AIDS Patient Care STDS. 2004;18(12):687-690.

98. Chen D, Misra A, Garg A. Clinical review 153: Lipodystrophy in human immunodeficiency virus-infected patients. J Clin Endocrinol Metab. 2002;87(11):4845-4856.

99. Negredo E, Molto J, Puig J, Cinquegrana D, Bonjoch A, Perez-Alvarez N, Lopez-Blazquez R, et al. Ezetimibe, a promising lipid-lowering agent for the treatment of dyslipidaemia in $\mathrm{HIV}$-infected patients with poor response to statins. AIDS. 2006;20(17):2159-2164.

100. Coll B, Aragones G, Parra S, Alonso-Villaverde C, Masana L. Ezetimibe effectively decreases LDL-cholesterol in HIV-infected patients. AIDS. 2006;20(12):16751677.

101. Patel SB. Ezetimibe: a novel cholesterol-lowering agent that highlights novel physiologic pathways. Curr Cardiol Rep. 2004;6(6):439-442.

102. Wohl DA, Waters D, Simpson RJ, Jr., Richard S, Schnell A, Napravnik S, Keys J, et al. Ezetimibe alone reduces low-density lipoprotein cholesterol in HIV-infected patients receiving combination antiretroviral therapy. Clin Infect Dis. 2008;47(8):1105-1108.

103. Chastain LM, Bain AM, Edwards KL, Bedimo R, Busti AJ. A retrospective study of the lipid-lowering efficacy and safety of ezetimibe added to hydroxy methylglutaryl coenzyme A reductase therapy in HIV-infected patients with hyperlipidemia. J Clin Lipidol. 2007;1(6):634-639.

104. Grandi AM, Nicolini E, Rizzi L, Caputo S, Annoni F, Cremona AM, Marchesi C, et al. Dyslipidemia in HIVpositive patients: a randomized, controlled, prospective study on ezetimibe+fenofibrate versus pravastatin monotherapy. J Int AIDS Soc. 2014; 17:19004.

105. Zinn RJ, Serrurier C, Takuva S, Sanne I, Menezes CN. HIV-associated lipodystrophy in South Africa: the impact on the patient and the impact on the plastic surgeon. J Plast Reconstr Aesthet Surg. 2013;66(6):839-844.

106. Gallego-Escuredo JM, Domingo P, Fontdevila J, Villarroya J, Domingo JC, Martinez E, Giralt M, et al. Hypertrophied facial fat in an HIV-1-infected patient after autologous transplantation from 'buffalo hump' retains a partial brown-fat-like molecular signature. Antivir Ther. 2013;18(4):635-639.

107. Hultman CS, McPhail LE, Donaldson JH, Wohl DA. Surgical management of HIV-associated lipodystrophy: role of ultrasonic-assisted liposuction and suction-assisted lipectomy in the treatment of lipohypertrophy. Ann Plast Surg. 2007;58(3):255-263.

108. Tsoukas MA, Farr OM, Mantzoros CS. Leptin in congenital and HIV-associated lipodystrophy. Metabolism. 2015;64(1):47-59.

109. Chou K, Perry CM. Metreleptin: first global approval. Drugs. 2013;73(9):989-997.

110. Grinspoon S, Corcoran C, Lee K, Burrows B, Hubbard J, Katznelson L, Walsh M, et al. Loss of lean body and muscle mass correlates with androgen levels in hypogonadal men with acquired immunodeficiency syndrome and wasting. J Clin Endocrinol Metab. 1996;81(11):40514058.

111. Dobs AS, Few WL, 3rd, Blackman MR, Harman SM, Hoover DR, Graham NM. Serum hormones in men with human immunodeficiency virus-associated wasting. J Clin Endocrinol Metab. 1996;81(11):4108-4112.

112. Crum NF, Furtek KJ, Olson PE, Amling CL, Wallace MR. A review of hypogonadism and erectile dysfunction among HIV-infected men during the pre- and postHAART eras: diagnosis, pathogenesis, and management. AIDS Patient Care STDS. 2005;19(10):655-671.

113. Mauras N, Martinez V, Rini A, Guevara-Aguirre J. Recombinant human insulin-like growth factor I has significant anabolic effects in adults with growth hormone receptor deficiency: studies on protein, glucose, and lipid metabolism. J Clin Endocrinol Metab. 2000;85(9):30363042.

114. Kong A, Edmonds P. Testosterone therapy in HIV wasting syndrome: systematic review and meta-analysis. Lancet Infect Dis. 2002;2(11):692-699.

115. Badowski M, Pandit NS. Pharmacologic management of human immunodeficiency virus wasting syndrome. Pharmacotherapy. 2014;34(8):868-881.

116. Grinspoon S, Corcoran C, Askari H, Schoenfeld D, Wolf L, Burrows B, Walsh M, et al. Effects of androgen administration in men with the AIDS wasting syndrome. A randomized, double-blind, placebo-controlled trial. Ann Intern Med. 1998;129(1):18-26.

117. Bhasin S, Parker RA, Sattler F, Haubrich R, Alston B, Umbleja T, Shikuma CM. Effects of testosterone supplementation on whole body and regional fat mass and distribution in human immunodeficiency virus-infected men with abdominal obesity. J Clin Endocrinol Metab. 2007;92(3):1049-1057.

118. Gooren LJ, Bunck MC. Androgen replacement therapy: present and future. Drugs. 2004;64(17):1861-1891.

119. Berger JR, Pall L, Hall CD, Simpson DM, Berry PS, Dudley R. Oxandrolone in AIDS-wasting myopathy. AIDS. 1996;10(14):1657-1662.

120. Shevitz AH, Wilson IB, McDermott AY, Spiegelman D, Skinner SC, Antonsson K, Layne JE, et al. A comparison of the clinical and cost-effectiveness of 3 intervention strategies for AIDS wasting. J Acquir Immune Defic Syndr. 2005;38(4):399-406.

121. Grunfeld C, Kotler DP, Dobs A, Glesby M, Bhasin S. Oxandrolone in the treatment of HIV-associated weight loss in men: a randomized, double-blind, placebo-controlled study. J Acquir Immune Defic Syndr. 2006;41(3):304314.

122. Hengge UR, Stocks K, Wiehler H, Faulkner S, Esser S, Lorenz C, Jentzen W, et al. Double-blind, randomized, placebo-controlled phase III trial of oxymetholone for the treatment of HIV wasting. AIDS. 2003;17(5):699-710.

123. Blackman MR. Manipulation of the growth hormone axis in patients with HIV infection. $\mathrm{N}$ Engl J Med. 2007;357(23):2397-2399.

124. Lo J, You SM, Canavan B, Liebau J, Beltrani G, Koutkia P, Hemphill L, et al. Low-dose physiological 
growth hormone in patients with HIV and abdominal fat accumulation: a randomized controlled trial. JAMA. 2008;300(5):509-519.

125. Mulligan K, Grunfeld C, Hellerstein MK, Neese RA, Schambelan M. Anabolic effects of recombinant human growth hormone in patients with wasting associated with human immunodeficiency virus infection. J Clin Endocrinol Metab. 1993;77(4):956-962.

126. Krentz AJ, Koster FT, Crist DM, Finn K, Johnson LZ, Boyle PJ, Schade DS. Anthropometric, metabolic, and immunological effects of recombinant human growth hormone in AIDS and AIDS-related complex. J Acquir Immune Defic Syndr. 1993;6(3):245-251.

127. Schambelan M, Mulligan K, Grunfeld C, Daar ES, LaMarca A, Kotler DP, Wang J, et al. Recombinant human growth hormone in patients with HIV-associated wasting. A randomized, placebo-controlled trial. Serostim Study Group. Ann Intern Med. 1996;125(11):873-882.

128. Kotler DP, Muurahainen N, Grunfeld C, Wanke C, Thompson M, Saag M, Bock D, et al. Effects of growth hormone on abnormal visceral adipose tissue accumulation and dyslipidemia in HIV-infected patients. J Acquir Immune Defic Syndr. 2004;35(3):239-252.

129. Esposito JG, Thomas SG, Kingdon L, Ezzat S. Anabolic growth hormone action improves submaximal measures of physical performance in patients with HIVassociated wasting. Am J Physiol Endocrinol Metab. 2005;289(3):E494-503.

130. Falutz J, Allas S, Kotler D, Thompson M, Koutkia P, Albu J, Trottier B, et al. A placebo-controlled, dose-ranging study of a growth hormone releasing factor in HIV-infected patients with abdominal fat accumulation. AIDS. 2005;19(12):1279-1287.

131. Bedimo R. Growth hormone and tesamorelin in the management of HIV-associated lipodystrophy. HIV AIDS (Auckl). 2011;3:69-79.

132. Spooner LM, Olin JL. Tesamorelin: a growth hormonereleasing factor analogue for HIV-associated lipodystrophy. Ann Pharmacother. 2012;46(2):240-247.

133. Rao MN, Mulligan K, Tai V, Wen MJ, Dyachenko A, Weinberg M, Li X, et al. Effects of insulin-like growth factor (IGF)-I/IGF-binding protein-3 treatment on glucose metabolism and fat distribution in human immunodeficiency virus-infected patients with abdominal obesity and insulin resistance. J Clin Endocrinol Metab. 2010;95(9):4361-4366.

134. Lagathu C, Bastard JP, Auclair M, Maachi M, Kornprobst M, Capeau J, Caron M. Antiretroviral drugs with adverse effects on adipocyte lipid metabolism and survival alter the expression and secretion of proinflammatory cytokines and adiponectin in vitro. Antivir Ther. 2004;9(6):911-920.

135. Kaplan G, Thomas S, Fierer DS, Mulligan K, Haslett PA, Fessel WJ, Smith LG, et al. Thalidomide for the treatment of AIDS-associated wasting. AIDS Res Hum Retroviruses. 2000;16(14):1345-1355.

136. Yarasheski KE, Tebas P, Stanerson B, Claxton S, Marin D, Bae K, Kennedy M, et al. Resistance exercise training reduces hypertriglyceridemia in $\mathrm{HIV}$-infected men treated with antiviral therapy. J Appl Physiol (1985). 2001;90(1):133-138.

137. Terry L, Sprinz E, Stein R, Medeiros NB, Oliveira J, Ribeiro JP. Exercise training in HIV-1-infected individuals with dyslipidemia and lipodystrophy. Med Sci Sports Exerc. 2006;38(3):411-417.

138. Lindegaard B, Hansen T, Hvid T, van Hall G, Plomgaard P, Ditlevsen S, Gerstoft J, et al. The effect of strength and endurance training on insulin sensitivity and fat distribution in human immunodeficiency virus-infected patients with lipodystrophy. J Clin Endocrinol Metab. 2008;93(10):3860-3869.

139. Barrios A, Blanco F, Garcia-Benayas T, Gomez-Viera JM, de la Cruz JJ, Soriano V, Gonzalez-Lahoz J. Effect of dietary intervention on highly active antiretroviral therapy-related dyslipemia. AIDS. 2002;16(15):2079-2081.

140. Ng GW, Chan UM, Li PC, Wong WC. Can a Mediterranean diet reduce the effects of lipodystrophy syndrome in people living with HIV? A pilot randomised controlled trial. Sex Health. 2011;8(1):43-51.

141. Roubenoff R, Schmitz H, Bairos L, Layne J, Potts E, Cloutier GJ, Denry F. Reduction of abdominal obesity in lipodystrophy associated with human immunodeficiency virus infection by means of diet and exercise: case report and proof of principle. Clin Infect Dis. 2002;34(3):390393.

142. Benedini S, Perseghin G, Terruzzi I, Scifo P, Invernizzi PL, Del Maschio A, Lazzarin A, et al. Effect of L-acetylcarnitine on body composition in HIV-related lipodystrophy. Horm Metab Res. 2009;41(11):840-845.

143. Walker UA, Venhoff N, Koch EC, Olschewski M, Schneider J, Setzer B. Uridine abrogates mitochondrial toxicity related to nucleoside analogue reverse transcriptase inhibitors in HepG2 cells. Antivir Ther. 2003;8(5):463470.

144. McComsey GA, O'Riordan M, Setzer B, Lebrecht D, Baron E, Walker UA. Uridine supplementation in HIV lipoatrophy: pilot trial on safety and effect on mitochondrial indices. Eur J Clin Nutr. 2008;62(8):1031-1037.

145. Wohl DA, McComsey G, Tebas P, Brown TT, Glesby MJ, Reeds D, Shikuma C, et al. Current concepts in the diagnosis and management of metabolic complications of HIV infection and its therapy. Clin Infect Dis. 2006;43(5):645653.

146. Kamanna VS, Kashyap ML. Mechanism of action of niacin. Am J Cardiol. 2008;101(8A):20B-26B.

147. Balasubramanyam A, Coraza I, Smith EO, Scott LW, Patel P, Iyer D, Taylor AA, et al. Combination of niacin and fenofibrate with lifestyle changes improves dyslipidemia and hypoadiponectinemia in HIV patients on antiretroviral therapy: results of "heart positive," a randomized, controlled trial. J Clin Endocrinol Metab. 2011;96(7):22362247.

148. Leite LH, Sampaio AB. Dietary calcium, dairy food intake and metabolic abnormalities in HIV-infected individuals. J Hum Nutr Diet. 2010;23(5):535-543.

149. Samaras K, Wand H, Law M, Emery S, Cooper DA, Carr A. Dietary intake in HIV-infected men with lipodystrophy: relationships with body composition, visceral fat, 
lipid, glucose and adipokine metabolism. Curr HIV Res. 2009;7(4):454-461.

150. Gerber JG, Kitch DW, Fichtenbaum CJ, Zackin RA, Charles S, Hogg E, Acosta EP, et al. Fish oil and fenofibrate for the treatment of hypertriglyceridemia in HIV-infected subjects on antiretroviral therapy: results of ACTG A5186. J Acquir Immune Defic Syndr. 2008;47(4):459466.

151. Harris WS. n-3 fatty acids and serum lipoproteins: human studies. Am J Clin Nutr. 1997;65(5 Suppl):1645S-1654S.

152. Phillipson BE, Rothrock DW, Connor WE, Harris WS, Illingworth DR. Reduction of plasma lipids, lipoproteins, and apoproteins by dietary fish oils in patients with hypertriglyceridemia. N Engl J Med. 1985;312(19):1210-1216.

153. Peters BS, Wierzbicki AS, Moyle G, Nair D, Brockmeyer N. The effect of a 12-week course of omega-3 polyunsaturated fatty acids on lipid parameters in hypertriglyceridemic adult HIV-infected patients undergoing HAART: a randomized, placebo-controlled pilot trial. Clin Ther. 2012;34(1):67-76.

154. Gavrila A, Tsiodras S, Doweiko J, Nagy GS, Brodovicz K, Hsu W, Karchmer AW, et al. Exercise and vitamin $\mathrm{E}$ intake are independently associated with metabolic abnormalities in human immunodeficiency virus-positive subjects: a cross-sectional study. Clin Infect Dis. 2003;36(12):1593-1601.

155. Itinoseki Kaio DJ, Rondo PH, Luzia LA, Souza JM, Firmino AV, Santos SS. Vitamin E concentrations in adults with HIV/AIDS on highly active antiretroviral therapy. Nutrients. 2014;6(9):3641-3652.

156. Sharma B. Oxidative stress in HIV patients receiving antiretroviral therapy. Curr HIV Res. 2014;12(1):13-21.

157. Adebiyi OO, Adebiyi OA, Owira PM. Naringin Reverses Hepatocyte Apoptosis and Oxidative Stress Associated with HIV-1 Nucleotide Reverse Transcriptase Inhibitors-Induced Metabolic Complications. Nutrients. 2015;7(12):10352-10368.

158. Oluwafeyisetan A, Olubunmi A, Peter O. Naringin Ameliorates HIV-1 Nucleoside Reverse Transcriptase Inhibitors- Induced Mitochondrial Toxicity. Curr HIV Res.
2016;14(6):506-516.

159. www.unaids.org/15 by 15-UNAIDS_march 2015.

160. Grinspoon S, Carr A. Cardiovascular risk and body-fat abnormalities in HIV-infected adults. $\mathrm{N}$ Engl J Med. 2005;352(1):48-62.

161. Spire B, Carrieri P, Sopha P, Protopopescu C, Prak N, Quillet C, Ngeth C, et al. Adherence to antiretroviral therapy in patients enrolled in a comprehensive care program in Cambodia: a 24-month follow-up assessment. Antivir Ther. 2008;13(5):697-703.

162. Fernandes AP, Sanches RS, Mill J, Lucy D, Palha PF, Dalri MC. Lipodystrophy syndrome associated with antiretroviral therapy in HIV patients: considerations for psychosocial aspects. Rev Lat Am Enfermagem. 2007;15(5):1041-1045.

163. Zhou J, Paton NI, Ditangco R, Chen YM, Kamarulzaman A, Kumarasamy N, Lee CK, et al. Experience with the use of a first-line regimen of stavudine, lamivudine and nevirapine in patients in the TREAT Asia HIV Observational Database. HIV Med. 2007;8(1):8-16.

164. Wohl DA, Brown TT. Management of morphologic changes associated with antiretroviral use in HIV-infected patients. J Acquir Immune Defic Syndr. 2008;49(Suppl 2):S93-S100.

165. Asensi V, Rego C, Montes AH, Collazos J, Carton JA, Castro MG, Alvarez V, et al. IL-1beta $(+3954 \mathrm{C} / \mathrm{T})$ polymorphism could protect human immunodeficiency virus (HIV)-infected patients on highly active antiretroviral treatment (HAART) against lipodystrophic syndrome. Genet Med. 2008;10(3):215-223.

166. Bonnet E, Bernard J, Fauvel J, Massip P, Ruidavets JB, Perret B. Association of APOC3 polymorphisms with both dyslipidemia and lipoatrophy in HAART-receiving patients. AIDS Res Hum Retroviruses. 2008;24(2):169171.

167. Guallar JP, Gallego-Escuredo JM, Domingo JC, Alegre M, Fontdevila J, Martinez E, Hammond EL, et al. Differential gene expression indicates that 'buffalo hump' is a distinct adipose tissue disturbance in HIV-1-associated lipodystrophy. AIDS. 2008;22(5):575-584. 